\title{
Advances in translational bioinformatics and population genomics in the Asia-Pacific
}

\author{
Shoba Ranagathan ${ }^{1,2^{*}}$, Sissades Tongsima ${ }^{3}$, Jonathan Chan ${ }^{4}$, Tin Wee Tan ${ }^{2,5}$, Christian Schönbach ${ }^{6,7^{*}}$ \\ From Asia Pacific Bioinformatics Network (APBioNet) Eleventh International Conference on Bioinformatics \\ (InCoB2012) \\ Bangkok, Thailand. 3-5 October 2012
}

\begin{abstract}
The theme of the 2012 International Conference on Bioinformatics (InCoB) in Bangkok, Thailand was "From Biological Data to Knowledge to Technological Breakthroughs." Besides providing a forum for life scientists and bioinformatics researchers in the Asia-Pacific region to meet and interact, the conference also hosted thematic sessions on the Pan-Asian Pacific Genome Initiative and immunoinformatics. Over the seven years of conference papers published in BMC Bioinformatics and four years in BMC Genomics, we note that there is increasing interest in the applications of -omics technologies to the understanding of diseases, as a forerunner to personalized genomic medicine.
\end{abstract}

\section{Background}

Since 1998, the Asia-Pacific Bioinformatics Network (APBioNet) [1] has worked towards fostering bioinformatics as a scientific discipline in the Asia-Pacific region. The International Conference of Bioinformatics (InCoB) series of conferences has served as the annual APBioNet conference since 2002, spanning an audience form students to experts from the life, computing, -omics and biomedical sciences. The progress of bioinformatics in the Asia-Pacific region as documented in the editorials of previous $\mathrm{InCoB}$ supplements in $B M C$ Bioinformatics and BMC Genomics Supplements have been summarized by Schönbach et al. [2], along with a detailed description of the 2012 conference at Bangkok, Thailand, Oct 3-5, 2012 and the review process for accepted conference papers, published in this supplement as well as in BMC Bioinformatics [2]. With the global trend towards personalized medicine, InCoB2012 supported presentations from the Pan Asia Population Genomics Initiative (PAPGI) [3]. A detailed report on

\footnotetext{
* Correspondence: shoba.ranganathan@mq.edu.au; schoen@bio.kyutech.ac.jp 'Department of Chemistry and Biomolecular Sciences and ARC Centre of Excellence, Macquarie University, Sydney, NSW 2109, Australia ${ }^{6}$ Department of Bioscience and Bioinformatics, Kyushu Institute of Technology, Fukuoka 820-8502, Japan Full list of author information is available at the end of the article
}

the two special PAPGI sessions is presented here, while the immunoinformatics session has been reported in BMC Bioinformatics [2].

APBioNet's $11^{\text {th }}$ International Conference on Bioinformatics [4] was held in Bangkok, Thailand on Oct 3-5, 2012. with two satellite meetings the 3rd International Conference on Computational Systems Biology and Bioinformatics (CSBio2012) and the 3rd Winter Conference of the International Neural Networks Society (INNS-WC2012) co-hosted by Thailand's National Center for Genetic Engineering and Biotechnology (BIOTEC), as well as the King Mongkut's University of Technology Thonburi (KMUTT). Keynote addresses covered the development of bioinformatics as a research discipline in Thailand, comparative genomics of micobes and their global catalogue, computational drug design, genome-wide association studies, disease-based genome variations and the milestones and future of genomic medicine.

\section{Pan Asia Population Genomics Initiative (PAPGI) session report}

InCoB2012 hosted a special forum, organized by PAPGI researchers. PAPGI, formerly known as the Pan Asian SNP Initiative (PASNP), is a collaborative project that strives to explain the Pan Asian continuous spectrum of

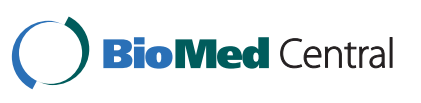

(c) 2012 Ranagathan et al.; licensee BioMed Central Ltd. This is an open access article distributed under the terms of the Creative Commons Attribution License (http://creativecommons.org/licenses/by/2.0), which permits unrestricted use, distribution, and reproduction in any medium, provided the original work is properly cited. 
phenotypic traits by deciphering the underlying population genomic diversity. In 2009, the consortium published the fundamental prediction of Asian migration history [5] using the genotyping information of 1,928 individuals. In this project, PAPGI researchers plan to use Next Generation Sequencing (NGS) to uncover other uncommon variants that could further unravel patterns in genomic diversity. Several teleconferencing meeting were conducted over the past year to iron out agreements and research protocols in order to smoothly execute the sequencing project as well as post analyses of the sequencing data. During the two special sessions at InCoB2012, nine key researchers from PAPGI delivered talks about research progress, focusing on a proposed computational workflow to analyze the data. In particular, several new bioinformatics analytical pipelines based on graph theory were proposed to analyze the enormous NGS data from large number of individuals. Based on the fact that selfreported origins may not be accurate, unsupervised clustering using genetic diversity information should be used to re-cluster data into genetically similar groups [6]. There are also discussions on the progress of the NGS data generated from Singapore, Malaysia, and Kuwait. Furthermore, the data from PASNP were reanalyzed in different context that explain the local adaptation of Pan Asian population using their admixture history [7].

During the discussions, several issues including ratification of consensus agreement, sample selection criteria, collaboration with other countries/societies and external funding were raised. In particular, PAPGI will be officially affiliated to the Human Genome Organization (HUGO). The affiliation to the Asia Pacific Society of Human Genetics is being finalized. Since the samples used in PAPGI may be different from the ones used in the previous PASNP study and there are more countries, mainly from the Middle East participating in the project, issues about sample selection criteria was discussed and a general guideline for PAPGI sample selection will be drafted.

\section{Overview of InCoB2012 accepted papers}

Of the 53 accepted proceedings papers 25 articles were published in the BMC Bioinformatics Vol. 13 Supplement 17 [2] while the remaining 28 articles in this issue are presented thematically.

\section{Genomics}

Piriyapongsa et al. [8] present iLOCi, a new approach for detecting epistasis in genome-wide association studies, while Jensen et al. [9] have predicted bacterial growth from geneomic sequences, using a Bayesian approach. Chen et al. [10] have carried out bacterial whole genome sequencing to identify pathogenicity-related genesm while Chu et al. [11] have developed MitoCounter to quantitaively report mitochondrial DNA copy numbers, important for aging dosorders. snpTree [12] is a new rapid standardised and automatic SNP analysis approach for epidemiological studies while 454 pyrosequencing, coupled with bioinformatics analysis, has been effectively used to sequence the dengue virus quasispecies [13].

\section{Transcriptomics}

Garg and Ranganathan [14] have developed a helminth secretome database from EST sequences, whereas Chen et al. [15] present FastAnnotator for efficient transcript annotation. Menon et al. [16] have reported the largescale annotation of the transcriptome of an economically important parasitic nematode. Vandenbon et al. [17] have systematically identified transcription factor pairs significantly co-occurring in a set of promoter sequences. Wu et al. [18] have uncovered novel multi-cancer differentially expressed gene candidates using meta-analytical biomarker search of EST expression data.

\section{miRNA and sRNA}

Khoo et al. [19] report the computational indentification and experimental validation of small RNAs (sRNAs) from Burkholderia pseudomallei, a soil bacterium which causes the disease melioidosis. Yang et al. [20] have proposed genetic buffering roles of for human microRNAs (miRNAs) on genome expression fluctuation. miRNAs can be used to design virus vaccines [21] while miRNAs and their targets can be rapidly identified even in plants [22]. Lee et al. [23] have developed a comprehensive analytical approach for the functional annotation of miRNAs, while Chang et al. [24] have analyzed miRNAs in breast cancer.

\section{Proteins, ligands, docking and virtual screening}

Ali et al. [25] have developed organism-specific substitution matrices for improved protein annotation, while Grover et al. [26] report mechanistic insights into the anti-leishmanial activity of prospective herbal drugs. Chiu et al. [27] report pahrmaceutical motifs for rapid identification of target proteins.

\section{Mutations}

Kumar et al. [28] have engineered aggregation-prone recombinant proteins for substrate recognition by GroEL, while Wozniak et al. [29] have presented their results on finding drug resistance associated mutations in bacterial strains.

\section{Pathways and networks}

Praneenararat et al. [30] present NaviClusterCS for interactive and multi-scale network navigation in the big data era while Hsu and Yang [31] have uncovered oathway cross-talks based on functional relations between pathways. Hwang [32] has compared five methods of pathwayaggregation for gene expression data and report the best two. Li and Li [33] have identified disease genes by merging genetype and poheotype data using multigraph networks. 


\section{Emerging technologies and applications}

To leverage on the newly developed cloud computing technology, Chang et al. [34]. have developed a de novo next-generation sequence assembler. An application of modern genome informatics to marine ecosystems is reported by Somboonna et al. [35], in their study of metagenomic profiles of free-living prokaryotes and eukaryotes in the coastal areas of Sichang Island in Thailand.

The best paper title was awarded to Li and Li for their advancement of disease gene identification using a new random walk model that allows cross-walking between phenotype and gene networks [33]. The runners-up were Teo et al. [36] and Abbas et al. [37], in the BMC Bioinformatics supplement.

\section{Future Conferences}

APBioNet participated recently in the 1st International Conference in Translational Biomedical Informatics (ICTBI; http://ictbi.imed-cn.org/) in Taicang, China. To follow the rising interest in biomedical and translational bioinformatics InCoB2013 will be hosted jointly with the 2nd ICTBI and is scheduled to be held September 18-21, 2013 in Suzhou, China. We also hope to support PAPGI session, bringing population genomics together with translational bioinformatics, in the quest for personalized genomics.

\section{Acknowledgements}

We are grateful to Sakarindr Bhumiratana, President of King Mongkut's University of Technology Thonburi (KMUTT), Thaweesak Koanantakool, President of National Science and Technology Development Agency and Kanyawim Kirtikara, Executive Director of National Center for Genetic Engineering and Biotechnology (BIOTEC) for supporting InCoB2012. Special thanks go to BIOTEC and Cluster and Program Management Office, NSTDA staff members Chutima Chaochaiya and Wannipha Tongsima for their administrative and managerial support and to all the students and members of NSTDA and KMUTT who assisted during various preparation phases and/or at the venue. We are very appreciative of the continuous support of Isobel Peters from Supplement Issue Office, BioMed Central Limited. Last but not least we thank the members of InCoB2012 Scientific Program Committee and additional expert referees (listed in the additional file in [2]) for their constructive and timely reviews.

This article has been published as part of BMC Genomics Volume 13 Supplement 7, 2012: Eleventh International Conference on Bioinformatics (InCoB2012): Computational Biology. The full contents of the supplement are available online at http://www.biomedcentral.com/bmcgenomics/ supplements/13/S7.
}

\footnotetext{
Author details

${ }^{1}$ Department of Chemistry and Biomolecular Sciences and ARC Centre of Excellence, Macquarie University, Sydney, NSW 2109, Australia. ${ }^{2}$ Department of Biochemistry, Yong Loo Lin School of Medicine, National University of Singapore, Singapore 117597, Republic of Singapore. ${ }^{3}$ National Center for Genetic Engineering and Biotechnology (BIOTEC), National Science and Technology Development Agency (NSTDA), Thailand Science Park, Pathumthani 12120, Thailand. ${ }^{4}$ School of Information Technology, King Mongkut's University of Technology Thonburi, Bangkok 10140, Thailand. ${ }^{5}$ Computational Resource Centre ( ${ }^{*}$ CRC), $A^{*}$ STAR, Singapore 138632, Republic of Singapore. ${ }^{6}$ Department of Bioscience and Bioinformatics, Kyushu Institute of Technology, Fukuoka 820-8502, Japan. ${ }^{7}$ Biomedical Informatics Research and Development Center, Kyushu Institute of Technology, Fukuoka 820-8502, Japan.
}

\section{Authors' contributions}

SR and CS wrote this editorial. SR, ST, TWT and CS served as co-editors for the InCoB2012 supplement issues with SR as the lead editor. CS and SR managed the manuscript submission, peer-review and editorial decision processes as superchairs of EasyChair Conference System.

\section{Competing interests}

The authors were organizers, co-chairs, and/or session chairs of InCoB2012. TWT is a founding Director of Asia Pacific Bioinformatics Network, Ltd. All authors declare they have no other conflict of interest.

Published: 13 December 2012

\section{References}

1. Asia-Pacific Bioinformatics Network. [http://www.apbionet.org/].

2. Schönbach C, Tongsima S, Chan J, Brusic V, Tan TW, Ranganathan S: InCoB2012 Conference: from biological data to knowledge to technological breakthroughs. BMC Bioinfomatics 2012, 13(Suppl 17):S1.

3. Pan-Asian Population Genomics Initiative. [http://papgi.org/].

4. $11^{\text {th }}$ International Conference on Bioinformatics. [http://www.incob2012. org/].

5. HUGO Pan-Asian SNP Consortium, Abdulla MA, Ahmed I, Assawamakin A, Bhak J, Brahmachari SK, et al: Mapping human genetic diversity in Asia. Science 2009, 326(5959):1541-1545.

6. Limpiti T, Intarapanich A, Assawamakin A, Shaw PJ, Wangkumhang P, Piriyapongsa J, et al: Study of large and highly stratified population datasets by combining iterative pruning principal component analysis and structure. BMC Bioinformatics 2011, 12:255.

7. Xu S, Pugach I, Stoneking M, Kayser M, Jin L, HUGO Pan-Asian SNP Consortium: Genetic dating indicates that the Asian-Papuan admixture through Eastern Indonesia corresponds to the Austronesian expansion. Proc Natl Acad Sci USA 2012, 109(12):4574-4579.

8. Piriyapongsa J, Ngamphiw C, Intarapanich A, Kulawonganunchai , Assawamakin A, Bootchai C, Shaw PJ, Tongsima S: iLOCi: a SNP interaction prioritization technique for detecting epistasis in genome-wide association studies. BMC Genomics 2012, 13(Suppl 7):S2.

9. Jensen $D B$, Vesth $T C$, Hallin P, Pedersen AG, Ussery DW: Bayesian prediction of bacterial growth temperature range based on genome sequences. BMC Genomics 2012, 13(Suppl 7):S3.

10. Chen YT, Peng HL, Shia WC, Hsu FR, Ken CF, Tsao YM, Chen CH, Liu CE, Hsieh MF, Chen HC, Tang CY, Ku TH: Whole-genome sequencing and identification of Morganella morganii KT pathogenicity-related genes. BMC Genomics 2012, 13(Suppl 7):S4.

11. Chu HT, Hsiao WL, Tsao TL, Chang CM, Liu YW, Fan CC, Lin H, Chang HH, Yeh TJ, Chen JC, Huang DM, Chen CC, Kao CY: Quantitative assessment of mitochondrial DNA copies from whole genome sequencing. $B M C$ Genomics 2012, 13(Suppl 7):S5.

12. Leekitcharoenphon C, Mortensen RK, Thomsen MCF, Friis C, Rasmussen S, Aarestrup FM: snpTree - a web-server to identify and construct SNP trees from whole genome sequence data. BMC Genomics 2012, 13(Suppl 7):S6.

13. Chin-inmanu K, Suttitheptumrong A, Sangsrakru D, Tangphatsornruang S, Tragoonrung S, Malasit P, Tungpradabkul S, Suriyaphol P: Feasibility of using 454 pyrosequencing for studying quasispecies of the whole dengue viral genome. BMC Genomics 2012, 13(Suppl 7):S7.

14. Garg G, Ranganathan S: Helminth secretome database (HSD): a collection of helminth excretory/secretory proteins predicted from expressed sequence tags (ESTs). BMC Genomics 2012, 13(Suppl 7):S8.

15. Chen TW, Gan RCR, Wu TH, Huang PJ, Lee CY, Chen YYM, Chen CC, Tang P: FastAnnotator- an efficient transcript annotation web tool. BMC Genomics 2012, 13(Suppl 7):S9.

16. Menon R, Gasser RB, Mitreva M, Ranganathan S: An analysis of the transcriptome of Teladorsagia circumcincta: its biological and biotechnological implications. BMC Genomics 2012, 13(Suppl 7):S10.

17. Vandenbon A, Kumagai Y, Akira S, Standley DM: A novel unbiased measure for motif co-occurrence predicts combinatorial regulation of transcription. BMC Genomics 2012, 13(Suppl 7):S11.

18. Wu TH, Chu LJ, Wang JC, Chen TW, Tien YJ, Lin WC, Ng WV: Metaanalytical biomarker search of EST expression data reveals three differentially expressed candidates. BMC Genomics 2012, 13(Suppl 7):S12.

19. Khoo JS, Chai SF, Mohamed R, Nathan S, Firdaus-Raih M: Computational discovery and RT-PCR validation of novel Burkholderia conserved and 
Burkholderia pseudomallei unique sRNAs. BMC Genomics 2012, 13(Suppl 7):S13.

20. Yang Z, Dong D, Zhang Z, Crabbe MJC, Wang L, Zhong Y: Preferential regulation of stably expressed genes in the human genome suggests a widespread expression buffering role of microRNAs. BMC Genomics 2012, 13(Suppl 7):S14.

21. Wichadakul $D$, Mhuanthong $W$, Jongkeawwattana A, Ingsriswang S: A computational tool for the design of live attenuated virus vaccine based on microRNA-mediated gene silencing. BMC Genomics 2012, 13(Suppl 7):S15.

22. Numnark $S$, Mhuanthong $W$, Ingsriswang $S$, Wichadakul D: C-mii: a tool for plant miRNA and target identification. BMC Genomics 2012, 13(Suppl 7): S16.

23. Lee SY, Sohn KA, Kim JH: MicroRNA-centric measurement improves functional enrichment analysis of co-expressed and differentially expressed microRNA clusters. BMC Genomics 2012, 13(Suppl 7):S17.

24. Chang HT, Li SC, Ho MR, Pan HW, Ger LP, Hu LY, Yu SY, Li WH, Tsai KW: Comprehensive analysis of microRNAs in breast cancer. BMC Genomics 2012, 13(Suppl 7):S18.

25. Ali J, Thummala SR, Ranjan A: The parasite specific substitution matrices improve the annotation of apicomplexan proteins. BMC Genomics 2012, 13(Suppl 7):S19.

26. Grover A, Katiyar SP, Jeyakanthan J, Dubey VK, Sundar D: Blocking Protein kinase $C$ signaling pathway: mechanistic insights into the antileishmanial activity of prospective herbal drugs from Withania somnifera. BMC Genomics 2012, 13(Suppl 7):S20.

27. Chiu YY, Lin CY, Lin CT, Hsu KC, Chang LZ, Yang JM: Space-related pharma-motifs for fast search protein binding motifs and polypharmacological targets. BMC Genomics 2012, 13(Suppl 7):S21.

28. Kumar V, Punetha A, Sundar D, Chaudhuri TK: In silico engineering of aggregation-prone recombinant proteins for substrate recognition by the chaperonin GroEL. BMC Genomics 2012, 13(Suppl 7):S22.

29. Wozniak M, Tiuryn J, Wong L: An approach to identifying drug resistance associated mutations in bacterial strains. BMC Genomics 2012, 13(Suppl 7):S23.

30. Praneenararat T, Takagi T, Iwasaki W: Integration of interactive, multi-scale network navigation approach with Cytoscape for functional genomics in the big data era. BMC Genomics 2012, 13(Suppl 7):S24.

31. Hsu CL, Yang UC: Discovering pathway cross-talks based on functional relations between pathways. BMC Genomics 2012, 13(Suppl 7):S25.

32. Hwang S: Comparison and evaluation of pathway-level aggregation methods of gene expression data. BMC Genomics 2012, 13(Suppl 7):S26.

33. Li Y, Li J: Disease gene identification by random walk on multigraphs merging heterogeneous genomic and phenotype data. BMC Genomics 2012, 13(Suppl 7):S27.

34. Chang YJ, Chen CC, Chen CL, Ho JM: A de novo next generation genomic sequence assembler based on string graph and mapreduce cloud computing framework. BMC Genomics 2012, 13(Suppl 7):S28,

35. Somboonna N, Assawamakin A, Wilantho A, Tangphatsornruang S, Tongsima S: Metagenomic profiles of free-living archaea, bacteria and small eukaryotes in coastal areas of Sichang Island, Thailand. BMC Genomics 2012, 13(Suppl 7):S29.

36. Teo CY, Shave S, Chor ALT, Salleh AB, Rahman MBBA, Walkinshaw MD, Tejo BA: Discovery of a new class of inhibitors for the protein arginine deiminase type 4 (PAD4) by structure-based virtual screening. BMC Bioinformatics 2012, 13(Suppl 17):S4.

37. Abbas MM, Abouelhoda M, Bahig HM: A hybrid method for the exact planted $(I, d)$ motif finding problem and its parallelization. $B M C$ Bioinformatics 2012, 13(Suppl 17):S10.

doi:10.1186/1471-2164-13-S7-S1

Cite this article as: Ranagathan et al:: Advances in translational

bioinformatics and population genomics in the Asia-Pacific. BMC Genomics 2012 13(Suppl 7):S1.

\section{Submit your next manuscript to BioMed Central and take full advantage of:}

- Convenient online submission

- Thorough peer review

- No space constraints or color figure charges

- Immediate publication on acceptance

- Inclusion in PubMed, CAS, Scopus and Google Scholar

- Research which is freely available for redistribution

Submit your manuscript at www.biomedcentral.com/submit
Biomed Central 